\title{
IPSILATERAL FRACTURE OF THE FEMUR AND TIBIA
}

\author{
R. D. FRASER, G. A. HUNTER, J. P. WADDELL \\ From the Orthopaedic Service, St Michael's Hospital, University of Toronto
}

The hospital records of $\mathbf{2 2 2}$ cases of ipsilateral fractures of the femur and tibia were reviewed, and patients were grouped according to the type of fracture and the method of treatment. Thirty-five per cent of patients required late operation for delayed union or non-union, osteomyelitis, refracture and malunion, regardless of the treatment group. A disturbing factor was the $\mathbf{3 0}$ per cent incidence of osteomyelitis in patients treated by fixation of both fractures, almost three times the incidence when only one fracture was fixed. A 30 per cent incidence of delayed union or non-union occurred in patients managed conservatively. Of sixty-three patients personally examined, the worst results found were those following conservative management of both fractures.

More use of rigid external fixation and of cast bracing is recommended in the management of the fractured tibia, combined with internal fixation of the femoral fracture. Examination of the knee suggested that, with ipsilateral fractures, disruption of ligaments is a common occurrence and should always be suspected.

There is little recorded in the English literature on the subject of ipsilateral fractures of the femur and tibia, a severe injury which appears to be increasing in frequency. Earlier papers have pointed out the high risk of complications and of permanent disability (Hayes 1961; Omer, Moll and Bacon 1968; Ratliff 1968; Winston 1972; Gillquist et al. 1973; McBryde and Blake 1974). Recently, Karlström and Olerud (1977) in a review of thirty-one patients, and Höjer, Gillquist and Liljedahl (1977) in a prospective study of twenty-one patients, have emphasised rigid fixation of both fractures as a means of obtaining excellent or good results.

We decided to review the experience of this dual injury in a number of centres, and to analyse the complications and results of treatment. Subsequent function of the knee has received little attention in the past, and we aimed to appraise it more fully. Most of the previous papers have been confined to shaft fractures of both bones, but in this review, fractures of the distal femur and of the proximal tibia were also included.

\section{MATERIAL}

The hospital records of 222 patients with simultaneous ipsilateral fractures of the femur and tibia, from injuries received between 1965 and 1975. were reviewed at thirteen teaching hospitals within Ontario and Quebec.

Males were involved four times as often as females, and more than half the patients were aged under twenty-five; the age range is shown in Figure 1. In seventy-eight cases a motor car was involved and in seventy a motor-cycle; sixty-four of the seventy motor-cyclists were less than twenty-five years old. Forty-two of the patients were pedestrians. The left lower limb was injured in 131 patients, the right in ninety-one.

In only one-third of patients was the injury restricted to one lower limb; in all the remainder therc were associated injuries elsewhere.

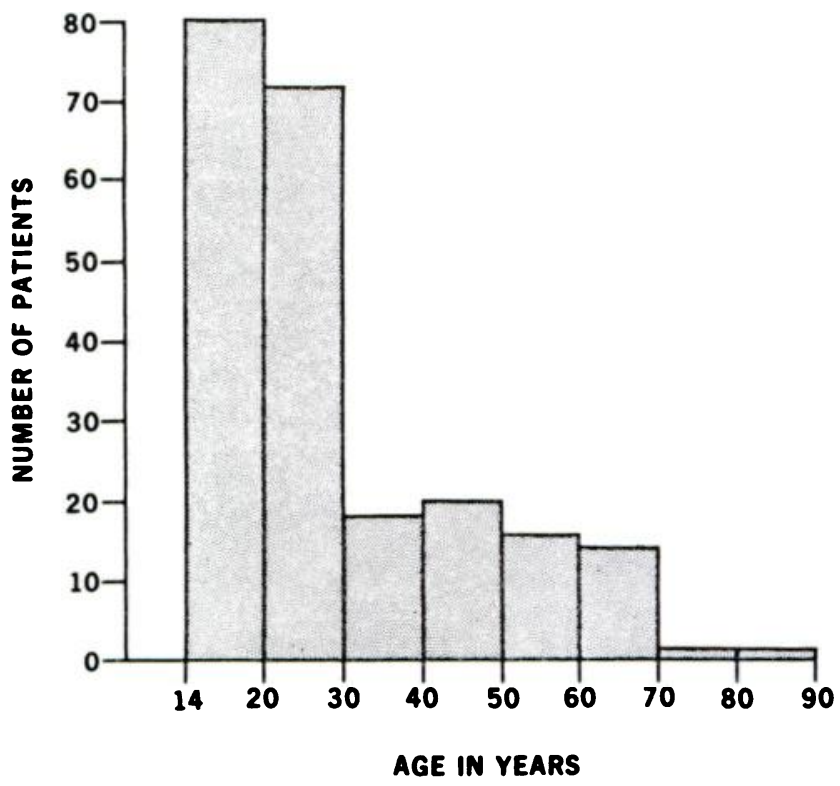

Fig. 1

Age distribution.

Sixty patients had intracranial damage and thirty-two had facial injuries. The chest was injured in twenty-two patients, the pelvis in thirty-three and the abdomen (including the genito-urinary tract) in

Robert Fraser, M.B., B.S., F.R.A.C.S., Division of Orthopaedics, Department of Surgery, Flinders Medical Centre, Bedford Park, Adelaide, South Australia 5042 .

Gordon Hunter, F.R.C.S., F.R.C.S.(C), Division of Orthopaedics, Department of Surgery, Sunnybrook Medical Centre, University of Toronto. Toronto, Ontario. Canada.

James Waddell. F.R.C.S.(C). Division of Orthopaedics, Department of Surgery, St Michael's Hospital, University of Toronto, Toronto, Ontario, Canada. 
nineteen. No fewer than 102 patients had musculoskeletal damage elsewhere in addition to the injured limb.

Classification. The patients were classified according to their fractures and according to involvement of the knee (Fig. 2). Type I (157 patients) had shaft fractures of both bones without extension of either fracture into the knee. Type II (sixty-five patients) had fractures which extended into the knee: in Type lla (thirty-seven patients) the tibial plateau was involved; in Type Ilb (ten patients) the lower femur; and in Type Ilc (eighteen patients) both sides of the knee had articular fractures. A number of the limbs with an articular fracture also had a fracture of the shaft, as indicated by the shaded areas in Figure 2. Segmental fractures occurred in thirty-three patients (femur twelve. tibia twenty-one).
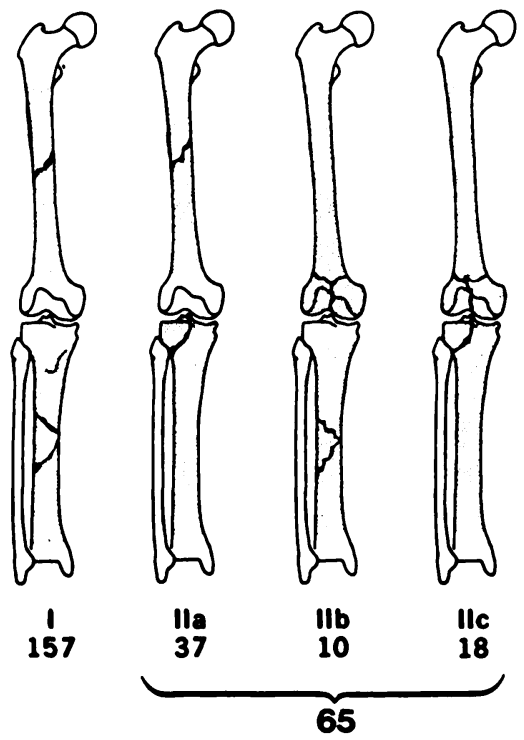

Fig. 2

Classification of fractures (222 patients).

Other features. One hundred and thirty-two patients ( 59 per cent) had compound fractures. The tibial fracture (109 patients) was more often compound than the femur (61 patients). Both femoral and tibial fractures were compound in thirty-eight patients.

Damage to major vessels occurred in sixteen patients; three femoral arteries were injured, four popliteal and nine tibial. Eight limbs required amputation, six within three weeks of injury and two for late complications of vascular insufficiency. Nerve injury occurred in fourteen patients; the lateral popliteal was involved in half the cases.

Ligamentous disruption of the knee was diagnosed early (within three weeks) in six patients, and later (after six weeks) in eleven. The incidence of ligamentous laxity at follow-up was almost five times as high as the incidence of previously diagnosed ligamentous tears, clearly implying that many of these injuries had been missed.

\section{TREATMENT}

The pattern of management of the fractures was established by the end of the third week (Table I); in only three patients was the management changed between three and six weeks. Femoral fractures were managed conservatively in 56 per cent of patients and by fixation in 44 per cent. Tibial fractures were managed by conservative means in 75 per cent of patients and by fixation (internal or external) in 25 per cent.

Patients were grouped according to the combined management of their fractures. In Group 1 (twentyseven patients) fixation of both femur and tibia had been
Table I. Treatment of the fractures in the first three weeks

\begin{tabular}{|l|r|r|}
\hline \multicolumn{1}{|c|}{ Method of treatment } & $\begin{array}{r}\text { Number } \\
\text { of femora }\end{array}$ & $\begin{array}{r}\text { Number } \\
\text { of tibiae }\end{array}$ \\
\hline Skeletal traction & 118 & 19 \\
Plaster & 6 & 119 \\
Plaster and incorporated skeletal pins & 1 & 24 \\
Intramedullary nail & 65 & 9 \\
Plates & 19 & 27 \\
Intramedullary nail and a plate & 4 & 0 \\
Screws or bolts & 6 & 12 \\
External fixator & 2 & 7 \\
Amputation & 1 & 5 \\
\hline
\end{tabular}

carried out. In Group 2 (ninety-two patients) one fracture only had been fixed. In Group 3 (ninety-nine patients) both fractures had been managed conservatively. Four patients were excluded because of early death or immediate amputation.

\section{COMPLICATIONS}

Nine patients died, five from brain damage, three from fat embolism and one from cardiac contusion. Other general complications included clinical fat embolism in twenty-one patients, pulmonary embolism in seven, renal failure in two and one patient developed gas gangrene.

\section{Local complications}

All local complications, except malunion and refracture, affected the tibia more often than the femur (Table II).

Table II. Local complications in all 222 patients

\begin{tabular}{|l|r|r|}
\hline & Femur & Tibia \\
\hline Osteomyelitis & 9 & 17 \\
Delayed union & 18 & 23 \\
Non-union & 8 & 18 \\
Malunion & 13 & 5 \\
Refracture & 10 & 8 \\
Compartment syndrome & 0 & 3 \\
Amputation & 2 & 6 \\
\hline
\end{tabular}

Osteomyelitis. In fractures managed conservatively or by an external fixator osteomyelitis developed in $2.5 \mathrm{per}$ cent of femora and in 6.5 per cent of tibiae. The incidence in fractures managed by internal fixation was 6.4 per cent of femora and 12.8 per cent of tibiae. The risk of a patient developing osteomyelitis in either was 12 per cent. Patients in Group 1, where both fractures 
had been fixed, had a disastrously high deep infection rate of 30 per cent (Table III), whereas patients with only one fracture fixed (Group 2) had a rate of 11 per cent, and conservatively managed patients (Group 3 ) had an 8 per cent incidence of bone infection.

Delayed union or non-union. This occurred in 26 per cent of patients. The incidence was least in Group 1 (15 per cent), and greatest in Group 3 (30 per cent) and was higher in conservatively managed fractures, 14 per cent of femora and 21 per cent of tibiae, than in those treated by fixation ( 10 per cent of femora and 11 per cent of tibiae).

Table III. Frequency of local complications and of late operations on bone

\begin{tabular}{|c|c|c|c|c|}
\hline & $\begin{array}{c}\text { Group 1 } \\
27 \text { patients }\end{array}$ & $\begin{array}{c}\text { Group 2 } \\
92 \text { patients }\end{array}$ & $\begin{array}{c}\text { Group 3 } \\
99 \text { patients }\end{array}$ & Average \\
\hline & Per cent & Per cent & Per cent & Per cent \\
\hline Osteomyelitis & 30 & 11 & 8 & 12 \\
\hline $\begin{array}{l}\text { Delayed or } \\
\text { non-union }\end{array}$ & 15 & 26 & 30 & 26 \\
\hline Malunion & 0 & 12 & 7 & 8 \\
\hline Refracture & 7 & 4 & 12 & 8 \\
\hline $\begin{array}{l}\text { Late bone operation } \\
\text { (excluding removal } \\
\text { of implants and } \\
\text { amputation) }\end{array}$ & 33 & 35 & 36 & 35 \\
\hline
\end{tabular}

Other complications. Unacceptable malunion was a problem in 8 per cent of patients, and refracture occurred in 8 per cent. A compartment syndrome was diagnosed and treated by fasciotomy in three patients. Amputation was required in eight patients: two above the knee, two through the knee and four below the knee.

As a result of these complications, 35 per cent of patients required late operation (excluding amputation and removal of internal fixation devices); this figure was almost identical in all three treatment groups (Table III). Treatment of bone infection was the predominant reason for further operation in Group 1, whereas delayed union or non-union was the main complication requiring operation (bone grafting, internal fixation or both) in Group 3.

\section{FOLLOW-UP}

Of the 222 patients in this series, only ninety-one were traceable, of whom sixty-three attended to be examined. However, we feel that these sixty-three were representative of the series in most respects. With one exception (McBryde and Blake 1974) previously reported series involved much smaller numbers of patients. All patients in this review were personally examined by the senior author (R. D. F.). The follow-up time ranged from two to twelve years with an average of almost five years.
Subjective findings. The time taken for patients to become mobile with aids varied from two weeks to seven months with an average of three months. From the patient's recollection of the time before weight-bearing without external support, an estimate was made of the healing time for each fracture; the average for both femur and tibia was over six months.

The time taken for patients to return to work varied from two weeks to eight years with an average of sixteen months; in both Group 1 and Group 2 the average was eleven months, while Group 3 patients took an average of twenty-one months to return to work. Nine patients had to change their occupation and five were still unemployed at the time of review.

The most common symptoms at the time of review involved the knee in 50 per cent and the ankle in 25 per cent; 25 per cent of patients complained of a limp (Table IV). Pain in the knee was the commonest symptom and was present in 37 per cent of patients. Five of the six patients who complained of pain in the hip had undergone intramedullary nailing of the femur. Half of the patients considered that their activity, in relation to work or sports, was still moderately or markedly reduced as a result of their injuries; this was regardless of the treatment group to which they belonged.

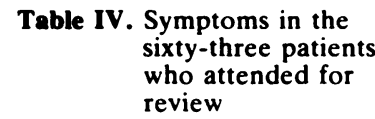

\begin{tabular}{|l|r|}
\hline Hip pain & 6 \\
Thigh pain & 3 \\
Knee - pain & 23 \\
-stiffness & 12 \\
- giving way & 3 \\
-swelling & 2 \\
- locking & 2 \\
Leg -pain & 7 \\
-swelling & 2 \\
Ankle-pain & 13 \\
-stiffness & 6 \\
-swelling & 2 \\
Limp & 16 \\
Weakness & 5 \\
Deformity & 1 \\
\hline
\end{tabular}

Objective findings. The main findings on examination are listed in Tables V and VI. Despite the high incidence of clinical deformity ( 27 per cent), only one patient complained of this, and her deformity was largely due to loss of soft tissue in the calf rather than to angulation at the site of the fracture. 
Table V. Clinical findings in the sixty-three patients reviewed

\begin{tabular}{|l|c|c|c|c|}
\hline & $\begin{array}{c}\text { Group 1 } \\
11 \text { patients }\end{array}$ & $\begin{array}{c}\text { Group 2 } \\
\text { 28 patients }\end{array}$ & $\begin{array}{c}\text { Group 3 } \\
24 \text { patients }\end{array}$ & Average \\
\hline $\begin{array}{l}\text { Obvious clinical } \\
\text { deformity }\end{array}$ & 18 & 29 & 29 & 27 \\
$\begin{array}{l}\text { Radiological } \\
\text { angulation (more } \\
\text { than 10 degrees) }\end{array}$ & 18 & Per cent & Per cent & Per cent \\
$\begin{array}{l}\text { Shortening (more } \\
\text { than 1 inch) }\end{array}$ & 36 & 11 & 29 & 22 \\
$\begin{array}{l}\text { Instability of the } \\
\text { knee }\end{array}$ & 36 & 43 & 35 & 39 \\
$\begin{array}{l}\text { Full knee movement } \\
\begin{array}{l}\text { Less than 90 } \\
\text { degrees of knee } \\
\text { movement }\end{array}\end{array}$ & 45 & 29 & 9 & 24 \\
Stiff ankle & 9 & 7 & 17 & 11 \\
Stiff subtalar joint & 9 & 29 & 43 & 30 \\
\hline
\end{tabular}

Table VI. Clinical findings in fifty-seven patients (all who attended for review. except those with articular fractures of both femur and tibia)

\begin{tabular}{|l|c|c|c|}
\hline & $\begin{array}{c}\text { Group 1 } \\
8 \text { patients }\end{array}$ & $\begin{array}{c}\text { Group 2 } \\
26 \text { patients }\end{array}$ & $\begin{array}{c}\text { Group 3 } \\
23 \text { patients }\end{array}$ \\
\hline Per cent & Per cent & Per cent \\
$\begin{array}{l}\text { Radinical deformity } \\
\text { (more than 10 degrees) } \\
\text { Full movement of the knee }\end{array}$ & 0 & 23 & 26 \\
$\begin{array}{l}\text { Less than 90 degrees of } \\
\text { knee movement }\end{array}$ & 0 & 42 & 43 \\
\end{tabular}

There was radiological evidence of angulation of more than 10 degrees in 38 per cent of patients. While as little as 5 degrees increase in tibial valgus was clinically obvious in one patient, gross radiological deformity was sometimes seen in a clinically undeformed limb. Group 1 patients had the least incidence of clinical and radiological deformity.

Shortening of the lower limb by one inch $(2.5$ centimetres) or more occurred in 22 per cent of patients (excluding amputees). The high incidence of shortening in Group 1 patients was primarily due to bone loss at the time of injury.

Ligamentous laxity of the knee, as compared with the other side, was present in 39 per cent of patients. In one third of these the laxity was marked. Only three patients complained of giving way of the knee; all three had marked laxity.

A full range of movement at the knee was found in only 24 per cent of patients, and restriction to less than 90 degrees in 11 per cent. Recovery of movement was best in Group 1 and worst in Group 3 (Table V). When Type IIc patients were excluded this trend was more obvious (Table VI).

Restriction of dorsiflexion of the ankle by 20 degrees or more was found in 32 per cent of patients, and restriction of the subtalar joint by half the normal range or more in 30 per cent.

The duration of immobilisation in plaster of knees which had stiffened (less than 90 degrees range of movement) was compared with that of fully mobile knees; similar comparisons were made at the ankle and subtalar joints. At all three joints stiffness was associated with a longer average immobilisation time than with joints which were fully mobile (Table VII).

Table VII. Average duration of plaster immobilisation (months)

\begin{tabular}{|l|c|c|c|}
\hline & Knee & Ankle & Subtalar \\
\hline Stiff joint & 5.2 & 7.8 & 7.1 \\
Mobile joint & 1.5 & 4.5 & 4.8 \\
\hline
\end{tabular}

Significant restriction of movement at the hip with pain was present in six patients, five of whom had undergone intramedullary nailing of the femur.

In five patients the foot was small and wasted, with tightness of the toe flexors attributed to ischaemic damage.

Assessment of results. Using the criteria for assessment described by Karlström and Olerud (1977), patients were graded as excellent, good, acceptable or poor (Table VIII). Excellent results were achieved in only three patients, all in Group 2. Fifteen patients were considered to have good results, thirty were acceptable and in fifteen the results were poor.

Good results were achieved in 30 per cent of patients in Group 1, in 36 per cent of Group 2 (including the three excellent results) and in 23 per cent of Group 3. Poor results occurred in 10 per cent of Group 1,11 per cent of Group 2 and in 36 per cent of Group 3. The three amputees, two of whom had their fractures treated

Table VIII. Assessment of results using the criteria of Karlström and Olerud (1977)

\begin{tabular}{|l|c|c|c|c|}
\hline & Group 1 & Group 2 & Group 3 & Total \\
\hline Excellent & 0 & 3 & 0 & 3 \\
Good & 3 & 7 & 5 & 15 \\
Acceptable & 6 & 15 & 9 & 30 \\
Poor & 1 & 3 & 8 & $\frac{15^{*}}{63}$ \\
& & & & \\
\hline
\end{tabular}

*This figure includes the three amputees 
conservatively, were not included in this grouping as the method of treatment of the fracture was not thought to have influenced the necessity for amputation.

\section{DISCUSSION}

Ipsilateral fracture of the femur and tibia is a serious injury which is often associated with other major injuries to the head, chest, viscera and musculoskeletal system. This review has not discussed the resuscitation of these multiple injuries, but mention must be made of the prime importance of this aspect of management in the light of the nine deaths and the twenty-one cases of clinical fat embolism in this series. Neurovascular injuries pose the main local threat to the limb. Half of the limbs complicated by vascular injury ultimately required amputation. Immediate assessment of the vascular status and appropriate treatment are essential if amputation is to be avoided.

The results of this review are disappointing. Thirty-five per cent of all patients required late operation (after six weeks) for delayed union or non-union, osteomyelitis, refracture or malunion. Of the sixty-three patients examined at follow-up 28 per cent were graded as excellent or good, 48 per cent acceptable, and 24 per cent had poor end-results. These results are inferior to the smaller series (thirty-one patients) of Karlström and Olerud (1977). Using the same system of grading they had 59 per cent good or excellent, 26 per cent acceptable and 15 per cent poor. As with our review their series also included fractures around the knee and not only shaft fractures. They found that rigid fixation of both bones resulted in excellent or good results in twelve out of fourteen patients.

Höjer et al. (1977) in a prospective study of twenty-one patients with shaft fractures of both bones, advocated immediate stabilisation of the tibia by internal or external means, followed by intramedullary fixation of the femur at seven to fourteen days. They found excellent functional results were achieved in most of their patients though their criteria for grading were not defined.

Ratliff (1968) reported that the best results were obtained with internal fixation of both fractures. He found good results in eleven of twelve limbs treated by internal fixation, compared with only three good results in the eleven patients treated conservatively.

The patients in this present review were managed at thirteen different teaching hospitals by a large number of surgeons. This probably explains why our complication rate and end-results differ from those in the two series just described.

The most alarming findings in our review was the disastrously high infection rate ( 30 per cent) in patients whose femur and tibia had both been fixed internally (Group 1), as compared with the infection rates in Group 2 (11 per cent) and Group 3 (8 per cent). Despite this, the over-all results in Group 1 were better than those in Group 3, which had a high proportion of poor results ( 36 per cent), largely due to a 30 per cent rate of delayed union or non-union. Another disturbing feature was the large number of patients ( 35 per cent) requiring secondary bone operations regardless of the treatment group.

It is apparent from previous papers (Ratliff 1968; Höjer et al. 1977; Karlström and Olerud 1977) that fixation of both bones can give better results than conservative management. In our series both the deep infection rate and the incidence of late operations were unacceptable in patients treated by fixation of both bones (Group 1), a finding which has not previously been reported. The incidence of bone infection (30 per cent) in Group 1 patients was almost three times as high as the incidence in Group 2 patients where only one fracture was fixed. When both fractures are fixed there is more demand on the surgeon and the theatre staff. The change of operative field and the more prolonged operating time lead to additional risks of wound contamination and perhaps to a less meticulous operation.

If fixation of both fractures is to be attempted, the operative conditions must clearly be good enough for rigid fixation to be achieved without risk of infection. Inadequate fixation is often far worse than no fixation at all; it leads to a high infection rate and to delayed union or non-union.

In view of our findings, we recommend that more use is made of rigid external fixation or of cast-bracing in the management of the fractured tibia, together with internal fixation of the femur; this combination allows early mobilisation of the patient and the knee.

In general, patients with articular fractures of both sides of the knee (Type IIc) did poorly in this series. The number at follow-up was too small to make definite recommendations regarding their management, though similar principles should be applied.

The common symptoms at follow-up were referred to the knee ( 50 per cent of patients) and ankle ( 25 per cent of patients); 25 per cent of patients complained of a limp.

The incidence of ligamentous laxity of the knee at follow-up ( 39 per cent) was almost five times as high as the incidence of ligamentous rupture diagnosed at the outset ( 8 per cent). While only a small number of patients at follow-up complained of giving way of the knee, the long-term effects of ligamentous laxity in contributing to early osteoarthritis must be taken into account. We suggest that the possibility of ligamentous disruption should always be thought of in patients with ipsilateral fracture of the femur and tibia. Stabilisation of one or both fractures is usually necessary before ligamentous integrity can be accurately tested.

Stiffness of the knee, ankle and subtalar joints was associated with more prolonged immobilisation than 
when these joints were mobile; this finding emphasises the benefit of early mobilisation of joints. More than half the patients in this series were under twenty-five years of age; stiffness of the knee or ankle can be an enormous handicap to these young patients, whose demands and expectations are high.

Our thanks are due to the surgeons throughout the teaching centres of Ontario and Quebec, who helped in this survey by allowing their patients to be reviewed. We would like to thank Professor Ian Macnab for his support of this project, and the Canadian Orthopaedic Foundation for financial help.

\section{REFERENCES}

Gillquist, J., Reiger, A.., Sjödahl, R., and Bylund, P. (1973) Multiple fractures of a single leg. A therapeutic problem. Acra Chirurgica Scandinavica, 139, 167-172.

Hayes. J. T. (1961) Multiple fractures in the same extremity: some problems in their management. Surgical Clinics of North America, 41, $1379-1388$

Höjer, H., Gillquist, J., and Liljedahl, S.-O. (1977) Combined fractures of the femoral and tibial shafts in the same limb. Injury, 8, 206-212.

Karlström, G., and Olerud, S. (1977) Ipsilateral fracture of the femur and tibia. Journal of Bone and Joint Surgery, 59-A, $240-243$.

McBryde, A. M., Jun., and Blake, R. (1974) The floating knee-ipsilateral fractures of the femur and tibia. Journal of Bone and Joint Surgery, 56-A, 1309

Omer, G. E., Jun., Moll, J. H., and Bacon, W. L. (1968) Combined fractures of the femur and tibia in a single extremity. Analytical study of cases at Brooke General Hospital from 1961 to 1967. Journal of Trauma, 8, 1026-1041.

Ratlif, A. H. C. (1968) Fractures of the shaft of the femur and tibia in the same limb. Proceedings of The Royal Society of Medicine, 61, 906-908.

Winston, M. E. (1972) The results of conservative treatment of fractures of the femur and tibia in the same limb. Surgery, Gynecology and Obstetrics. 134, 985-991. 